\title{
Advanced control of the cooling system in IC vehicles
}

\author{
Claudiu Muresan, Gabriel Harja, IOAN NașCu, \\ Department of Automation, Technical University of Cluj-Napoca \\ 26-28 G. Baritiu Street, 400027, Cluj-Napoca, \\ ROMANIA
}

\begin{abstract}
The cooling system of internal combustion (IC), electric or fuel cell vehicles is crucial. Not only that it avoids hazards and vehicle fails but it additionally provides the optimal operating temperature improving the reliability of the vehicle and reduced fuel consumption. The great nonlinearities, variable time constants and time delays present in the cooling system's model offers challenges from a control point of view. This paper provides a control strategy approach that can keep the optimal temperature regardless of the disturbances in the system and uses three control loops for the engine temperature, the temperature difference between engine inflow and outflow, and the temperature of the radiator outflow. The classical mechanical pump and thermostatic valve were replaced with their electrically actuated equivalent for better controllability. The control strategy was tested using realistic driving conditions provided by the New European Driving Cycle (NEDC).
\end{abstract}

Keywords-Engine cooling, cooling system, control system, heat exchangers.

Received: November 13, 2020. Revised: January 5, 2021. Accepted: February 2, 2021. Published: February 24, 2021.

\section{Introduction}

In an IC vehicle, due to the combustion process, power is produced. Only one third is converted to mechanical work used to move the vehicle while the rest is converted to heat [1]. Half of this leaves the engine through exhaust gases and the rest builds up in the engine block, thus raising the temperature of the engine. These high temperatures are transferred through cylinder wall liners to oil until it reaches the right viscosity, and the lubrication is done properly. Over this point the extra heat will bring damage to the engine's components. At such high temperatures the metal components will expand, friction will occur, lubricating oil will rapidly evaporate leading to sticking pistons and eventually damage [2]. To prevent such unwanted effects produced by the extra heat produced in combustion, the cooling system can cool the engine by transferring the thermal energy to the surrounding air passing through a radiator. Even if some of the total energy of the fuel is lost to the cooling system, this is necessary for each component to perform well over time, increasing the reliability and efficiency of the system.

A classical cooling system is usually composed of a water pump, radiator, thermostat, electrical fan, coolant reservoir and hoses. The water pump recirculates the coolant through the engine jacket removing the heat and transferring it to the radiator. In the radiator, heat is transferred through convection from the coolant to the walls and fins of the radiator. As the air flows through the radiator, the heat is transferred from radiator to the air. The thermostatic valve is responsible for regulating the flow rate that enters the radiator. This traditional cooling system has poor regulation capability as the pump speed is fixed by the engine speed and the thermostatic valve uses melting wax to open the valve. In [3] is estimated that engines are over-cooled for about $95 \%$ of their operating time. A comprehensive review of the impact of cooling systems on the efficiency of internal combustion engines is found in [4]. It is stated that the warm-up phase of the engine represents the major source of pollutants and low energy efficiency.
These limitations can be overcome by replacing the classical components with electrical actuated components such as electrical water pump and electrical three-way valve. These changes offer better controllability of the process with three manipulated variables: coolant flowrate developed by the pump, angle of the control valve and speed of the radiator's electric fan. Higher coolant flow rates increase the heat transfer rates between engine walls and coolant while lowering the time constants of the process. Modifying the angle of the control valve will determine the flow entering the radiator to be cooled down. The electric fan is critical in the situations when the vehicle is moving slowly or is being stopped and it assures airflow through the radiator in these situations. The main challenge is to find the right control strategy that will manipulate these parameters to ensure optimal operation of the engine with less pollutant products and better reliability and performance.

Explicit and well calibrated models for the cooling system offer great advantages in developing and testing the new control strategies. Thus, many researchers both from academic and industrial areas, have developed such mathematical models. The validated model of a 4-cylinder gasoline engine is presented in [5]. Another researcher [6] proposes a model for the cooling system that is calibrated based on data from a Citroen C3 1.4L TDI.

An efficient control strategy can be best tested in the two extreme situations: the slow uphill travel with a fully loaded vehicle on one hand and the high-speed traveling on the other. Such scenarios can be perfectly reproduced in simulations and different control algorithms can be realistically compared for efficiency. In [7] a study is presented on how the operation of the cooling system can improve the fuel consumption. To control the cooling system, the three-way valve is operated with a PD controller that uses an optimized parameter table. An improvement in fuel consumption of $1.5 \%$ for the urban mode, $1.42 \%$ for the extra-urban mode and $0.04 \%$ for the highway mode is obtained. In [8], the author chooses a 
complex control strategy using a robust model-based predictive control to reduce the warm-up time of the engine.

This paper continues the work started in [9] where a model for the cooling system was proposed and focuses mainly on the control strategies. Three PI control loops are being proposed: one for the engine temperature, one for the coolant temperature leaving the radiator and the last one is keeping the engine input and output temperature difference at a constant value. The last one is important especially for fuel cell vehicle where the temperature difference for proton exchange membrane needs to be under $10{ }^{\circ} \mathrm{C}$. Yet, stabilizing the temperature difference provides improved results in the case of IC vehicles. The control strategies are tested and compared using the New European Drive Cycle (NEDC).

\section{Previous Work}

The current work is based on the model described in [9] and focuses on the control of the cooling system of a typical automobile. In this section, the model is briefly presented along with the main equation that characterizes the physical phenomenon happening in this system. The circuit structure used in this model is shown in Fig. 1.

Thermal management systems traditionally were actuated by mechanical water pumps connected to the engine crankshaft through a belt and a thermostatic three-way valve that would open gradually starting with a lower limit temperature. These components were replaced with electrically actuated water pump and valve for a better controllability of the system and energy efficiency. The other components that involve heat transfer such as the engine and the radiator were modeled based on the principles of heat exchangers. The primary agent with a higher temperature, passes through the heat exchanger and is cooled due to the heat transfer to its walls. The secondary agent, with a lower temperature, captures the temperature of the walls as it passes through the heat exchanger.

The combustion that takes place in the engine is responsible for thermal power that is roughly one third of the engine power at any given moment [10]. The heat flow equation is presented in (1):

$$
Q_{\text {combustion }}=k \cdot m_{f u e l} \cdot Q_{H V}
$$

$m_{\text {fuel }}$ - fuel mass flow rate $(\mathrm{Kg} / \mathrm{s})$;

$Q_{H V}$ - Fuel heat value $(\mathrm{kJ} / \mathrm{kg})$;

$k$-Coefficient of the heat transfer combustion chamber to engine block.

The heat transferred from the engine to the cooling fluid:

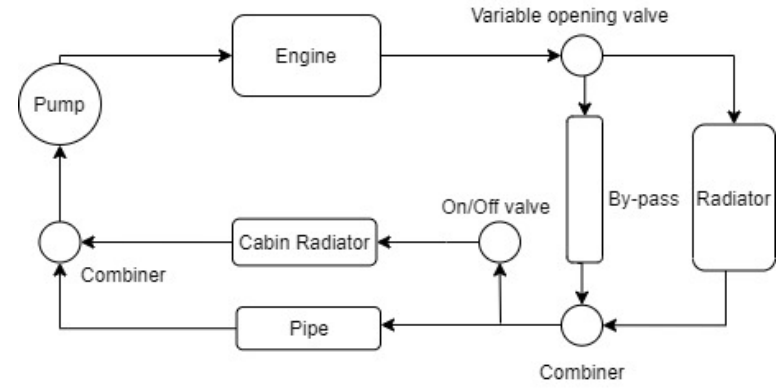

Fig. 1. Cooling system diagram

$$
Q_{\text {eng_to_water }}=k_{\text {water }} \cdot S \cdot \Delta T
$$

$k_{\text {water }}$ - Convective heat transfer coefficient $(\mathrm{W} / \mathrm{m} 2 \cdot \mathrm{K})$;

$S$ - Contact surface with the coolant (m2);

$\Delta T$ - The temperature difference across the exchange surface $\left(C^{o}\right)$.

The evolution of the engine temperature:

$$
\frac{d T_{\text {engine }}}{d t}=\frac{1}{m_{\text {eng }} \cdot C_{\text {peng }}} \cdot Q_{\text {engine }}
$$

$m_{\text {eng }}$ - engine mass $(\mathrm{Kg})$;

$C_{\text {peng }}$ - iron specific heat $(\mathrm{J} / \mathrm{Kg} \cdot \mathrm{K})$

Coolant is supposed to be non-compressible and is responsible only for heat transfer between components such as engine and radiator. Thus, the heat received from the engine block is transported to the radiator. At the radiator level the heat flows from water to metal block of the radiator and then from radiator to the moving air.

The evolution of temperature for water and air leaving the radiator is characterized by the following equation:

$$
\frac{d T_{\text {out }}}{d t}=\frac{q}{V}\left(T_{\text {in }}-T_{\text {out }}\right)-\frac{k \cdot S \cdot \Delta \mathrm{T}}{\rho \cdot V \cdot C p}
$$

while the temperature of the radiator walls is computed using equation (5):

$$
m_{\text {water }} C_{\text {prad }} \frac{d T_{\text {rad }}}{d t}=k_{\text {water }} S_{\text {water }} \Delta T_{1}-k_{\text {air }} S_{\text {air }} \Delta T_{2}
$$

The symbols in previous equations have the following meaning:

$$
\begin{aligned}
& q \text { - flow rate }(\mathrm{m} 3 / \mathrm{s}) ; \\
& V \text { - volume }(\mathrm{m} 3) ; \\
& k \text { - convective heat transfer coefficient }(\mathrm{W} / \mathrm{m} 2 \cdot \mathrm{K}) \text {; } \\
& \rho \text { - density }(\mathrm{Kg} / \mathrm{m} 3) ; \\
& C p \text { - specific heat }(\mathrm{J} / \mathrm{Kg} \mathrm{K}) ; \\
& m_{\text {rad }} \text { - water mass flow rate }(\mathrm{Kg} / \mathrm{s}) .
\end{aligned}
$$

In this model an electrical centrifugal pump is used. A $24 \mathrm{~V}$ electric motor drives the pump. The pump must overcome the pressure drop over the water circuit that is changing according to the valve openness degree. The overall pressure drop can be computed based on the loss on each component and using equation for serial or parallel arrangement.

The equations of the pump characteristics are displayed in a quadratic form and taking into consideration the equivalent pressure drop, the flow rate generated by the pump is computed using the equation:

$$
q=\frac{-B(n)-\sqrt{B(n)^{2}-4 \cdot(A(n)-K) \cdot C(n)}}{2 \cdot(A(n)-K)}
$$

where $\mathrm{K}$ - equivalent pressure drop, $\mathrm{n}$ - rpm of the pump and $\mathrm{A}, \mathrm{B}, \mathrm{C}$ are parameters of the pump curve characteristic as a function of rpm.

The three-way valve acts as a flow splitter based on the pressure loss through each branch. After passing through the 
radiator and bypass circuit, the coolant reaches a combiner where the mixed temperature is computed:

$$
T_{\text {out }}=\frac{T_{1} \cdot q_{1}+T_{2} \cdot q_{2}}{q_{1} \cdot q_{2}}
$$

Each pipe or volume is modeled as a variable delay block whose time delay is dependent on flowrate of the coolant.

All physical parameters and other values used in the modelling process can be found in [Muresan] together with the full presentation of the model.

The nonlinear behavior of the engine model is emphasized through a staircase experiment as in Fig 2. For this experiment, the engine model is initialized with the initial values such that the engine temperature is $90^{\circ} \mathrm{C}$. The input coolant temperature was kept constant and the coolant flow rate was varied.

A series of consecutive steps ("staircase event") on the coolant flowrate were applied, increasing the value of the coolant flow by a constant step. Thus, it is observed that the response of the system differs at each stage both in terms of amplitude and response time. As with the engine, the radiator has a non-linear behavior, and it was tested by a similar staircase experiment.

\section{Control Strategies}

Replacing the mechanical water pump and bypass valve with the electrical equivalent, gives more alternatives from the control point of view. This section illustrates the use of multiple PI controllers to control a complex system that is strongly coupled with large nonlinearities and variable dead time. PID controllers are classic control strategies that suit most of the processes in the industry.

All the simulations presented in this section, together with the modeling had been performed in Matlab/Simulink simulation platform.

Three control loops are proposed in this section as follows:

1) Engine outlet temperature control loop (EOT); This control loop manipulates the electrical bypass valve which in turn adjusts the coolant flowrate passing through the radiator. Thus the engine outlet temperature will remain constant at a temperature of $90^{\circ} \mathrm{C}$. The main purpose of this controller is to reject the perturbances that affect the outlet coolant temperature such as thermal power generated by the engine, air flow variations through radiator, variable coolant flowrate, etc.

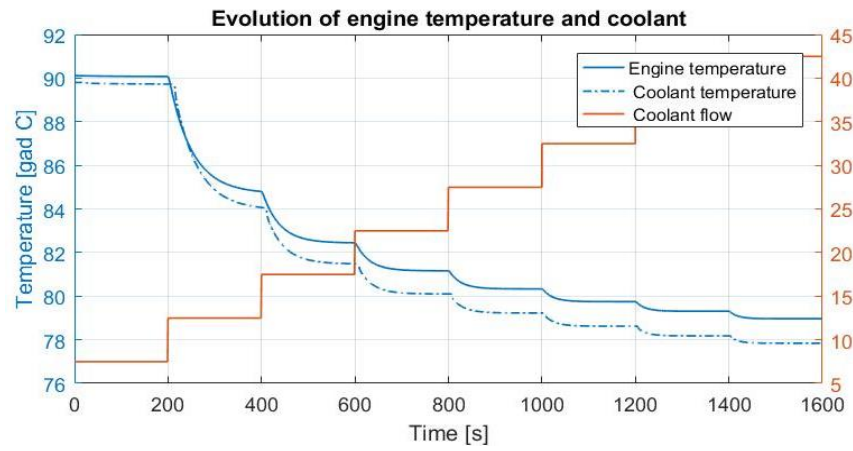

Fig. 2. Nonlinear behavior of engine temperature at different flow
Before implementing the control loop, a system identification process was carried out. The identified system has the openness degree of electrical bypass valve as input and the engine outlet temperature as output. From the step response of the system, a linear model in the form of a first order transfer function was obtained. This simulation was performed considering that the vehicle speed is $V_{v e h}=$ $50 \mathrm{~km} / \mathrm{h}$, initial bypass valve position $B y p=0.88$, water pump speed $n_{\text {pump }}=2500 R P M$, and thermal power generated by the engine is $Q_{\text {engine }}=10 \mathrm{~kW}$. The resulted transfer function can be seen in (8). The imposed design parameter is the time response of the system that will result in the closed loop transfer function in (9).

$$
\begin{gathered}
H_{\text {byp }}=\frac{k_{\text {byp }}}{T_{\text {byp }} s+1}=\frac{345}{285 s+1} \\
H_{0}=\frac{k_{\text {byp }}}{T_{\text {byp }} s+1}=\frac{1}{15 s+1}
\end{gathered}
$$

Using (10) the PI control parameters were obtained:

$$
H_{C_{-} \text {byp }}=\frac{1}{H_{\text {byp }}} \cdot \frac{H_{0}}{1-H_{0}}=0.055\left(1+\frac{0.0035}{s}\right)
$$

The performance of the control loop was tested for multiple reference steps around the operating point as shown in Fig. 3.

2) Radiator outlet temperature control loop (ROT); The purpose of this control loop is to keep the coolant temperature exiting the radiator under a certain reference value manipulating the radiator's fan speed. The benefit is visible when the vehicle is stationary, and no airflow is passing through the radiator. It prevents the engine to overheat. Similarly, the system was approximated by a first order transfer function (11). The identification process was performed using the step response of the system around stationary conditions. The vehicle speed is $V_{v e h}=0 \mathrm{~km} / \mathrm{h}$, bypass valve position $B y p=0.86$, water pump speed $n_{\text {pump }}=$ $2500 R P M$, thermal power generated by the engine is $Q_{\text {engine }}=$ $10 \mathrm{~kW}$ and initial fan PWM duty cycle is $D C_{\text {fan }}=0.5$. After choosing the Closed loop performance in (12), the PI parameters resulted in (13).

$$
\begin{gathered}
H_{\text {fan }}=\frac{-32}{11 s+1} \\
H_{0}=\frac{1}{1 s+1} \\
H_{C_{-} \text {fan }}=-0.3438\left(1+\frac{0.09}{s}\right)
\end{gathered}
$$
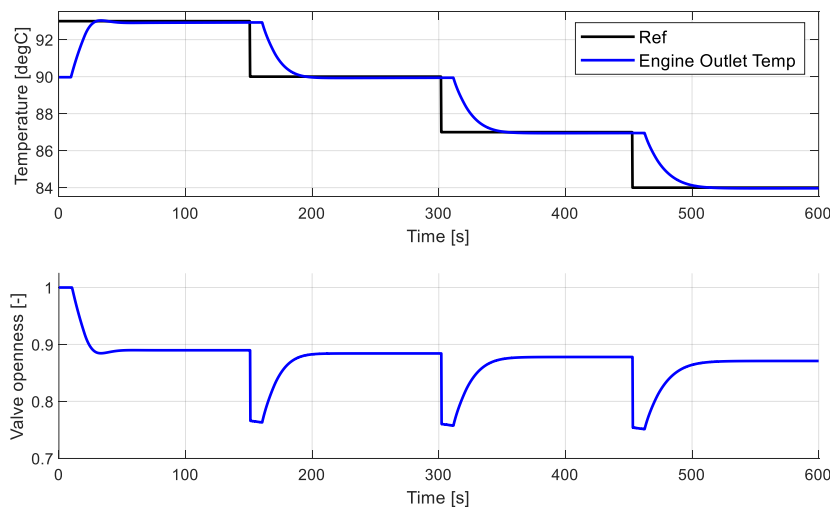

Fig. 3. Engine outlet temperature response for a closed loop staircase reference. 

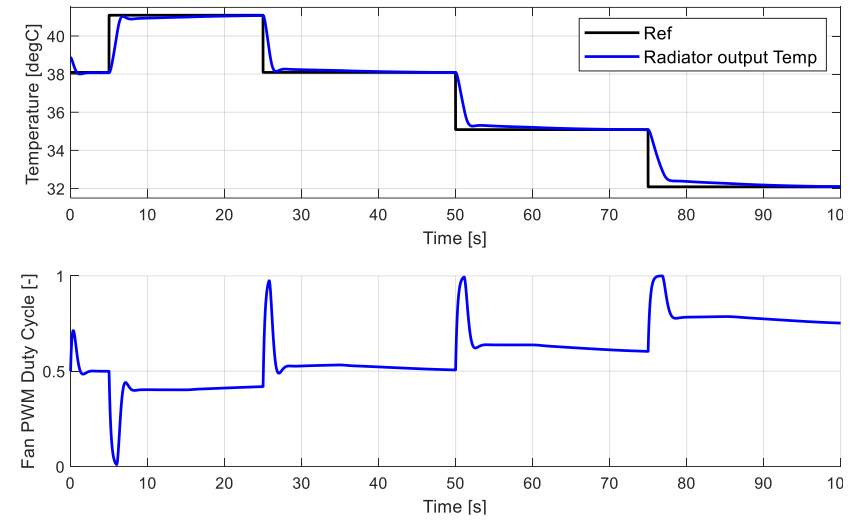

Fig. 4. Radiator outlet temperature evolution for a closed loop staircase reference

The performance of the control loop was tested for multiple reference steps around the operating point as shown in Fig. 4.

3) Engine temperature difference control loop (ETD); As the bypass valve changes its positon to overcome the disturbances, the coolant temperature diference between the outlet and inlet of the engine is also changing. It gets larger as the generated heat in the engine is increased. This temperature difference can be controlled by the water pump flowrate so that little heat generated results in small flowrates and large quantities of heat require greater flowrates. Thus, the input of the process is pump speed and the output is the temperature difference. For the identification process the following parameters were used: vehicle speed $\mathrm{V}_{\mathrm{veh}}=$ $50 \mathrm{~km} / \mathrm{h}$, bypass valve position Byp $=0.88$, initial water pump speed $\mathrm{n}_{\text {pump }}=2500 \mathrm{RPM}$, and thermal power generated by the engine $Q_{\text {engine }}=10 \mathrm{~kW}$. The linearized model of the prosess after step response identification is figured in (14) while the PI controller resulted in (16).

$$
\begin{gathered}
H_{\text {pump }}=\frac{-9}{269 s+1} \\
H_{0}=\frac{1}{30 s+1} \\
H_{C_{-} \text {pump }}=-0.996\left(1+\frac{0.0037}{s}\right)
\end{gathered}
$$

The control loop was first tested considering the other two controllers were turned off. Then, another test was carried out with the engine outlet temperature control loop enabled. The results are depicted in Fig. 5. It can be clearly seen that the two control loops are interconnected. Better performance is achieved when both controllers are enabled fact better demonstrated in the next section.

\section{Results}

This section provides a description of the control strategies performances in real conditions when driving the vehicle both in urban and extra urban conditions using the New European Drive Cycle (NEDC).

The NEDC is an important performance metric for evaluation of internal combustion engines efficiency. It simulates a range of driving scenarios from low-speed city driving to high-speed motorway cruising over a $1200 \mathrm{~s}$ period as shown by the speed trace in Fig. 6 [11]. In the European Union, fuel consumption of new engines is quantified using
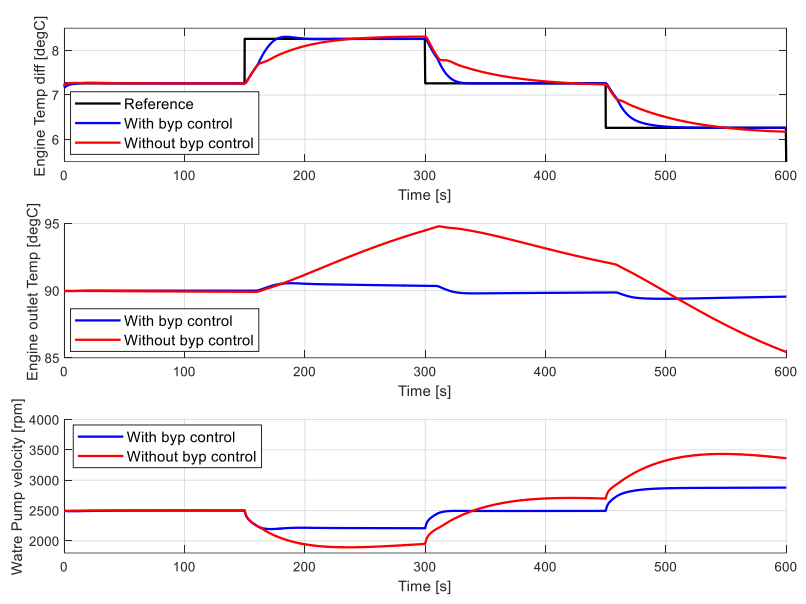

Fig. 5. Engine temperature difference evolution for a closed loop staircase reference

NEDC. Therefore, the proposed control strategies were tested together under realistic driving conditions used in the NEDC speed profile. The thermal power input is computed as fraction of the heat generated by the fuel burned during the driving cycle.

The last section presented the results of the individual control loops while this section provides a comparison of two control strategies as a mix of the three loops. In the first scenario, there will be a controller for the engine outlet temperature, one for the radiator outlet temperature and one for engine temperature difference. The second scenario excludes the latter controller, while the comparison itself will highlight the benefits of this control loop. Results of the comparison are depicted in Fig. 7 and Fig. 8. The blue signals are associated with the first scenario while the red signals are linked with the second scenario. All the controlled temperatures are displayed in Fig. 7 and the manipulated variables are displayed in Fig.8.

The ETD control loop manipulates the water pump velocity thus, generating variable flow rates. Lower flow rates result in bigger time constants and dead time values while an increased flow rate gives the advantage of lower time constants and dead time values.

In both scenarios the engine outlet temperature is kept around the reference in city driving conditions but for the extra urban conditions it is visible that the first control scenario gives better results. The maximum deviations from the setpoint are $\pm 3.7^{\circ} \mathrm{C}$ for first scenario and $\pm 7{ }^{\circ} \mathrm{C}$ for the second.

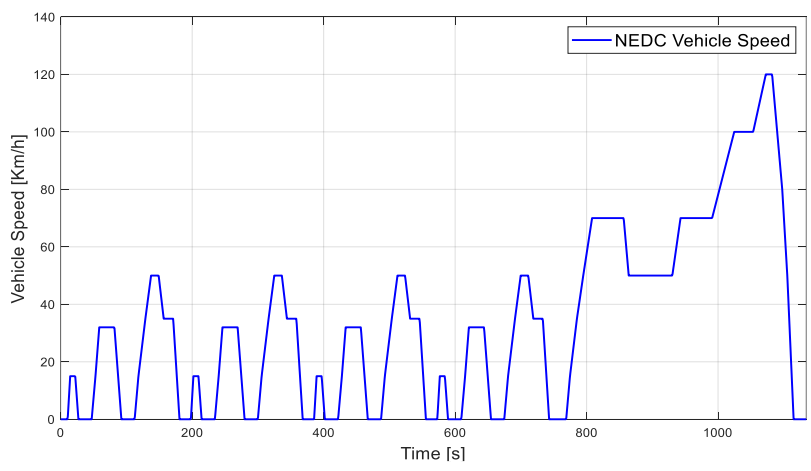

Fig. 6. Speed-time trace for the NEDC 

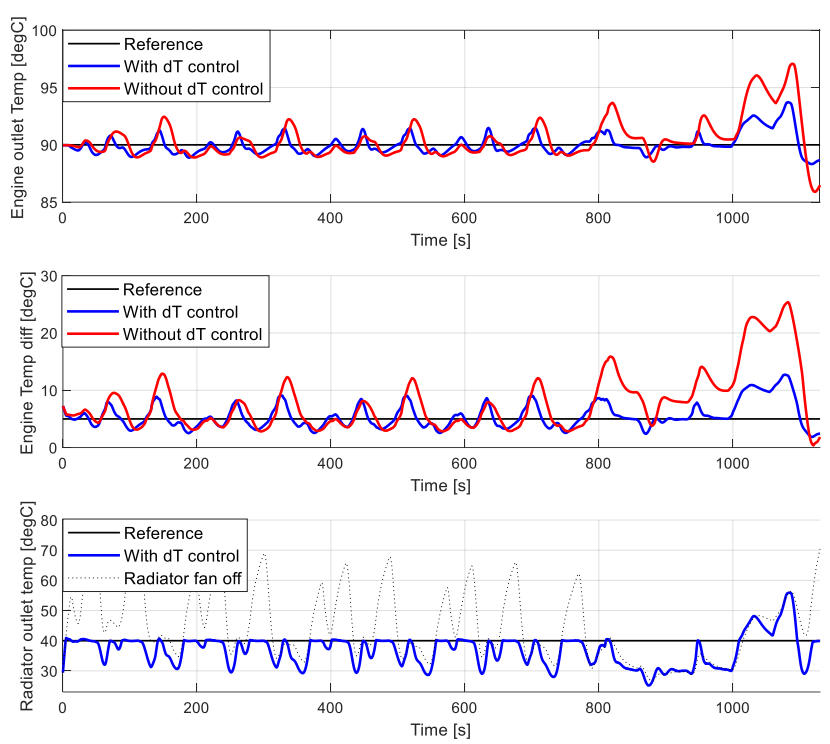

Fig. 7. Comparative results for engine outlet temperature (up), engine temperature difference (middle) and radiator outlet

Even larger difference between the two control scenarios can be seen in engine temperature difference where the maximum deviations are $\pm 7.7^{\circ} \mathrm{C}$ for first scenario and \pm 20.3 ${ }^{\circ} \mathrm{C}$ for the second. The extra urban driving conditions are challenging in this case also.

The radiator output temperature has larger values at low speed, and these are the moments when the radiator's fan is enabled to provide additional airflow through radiator. Without the ROT control loop the output temperature raises up to $70^{\circ} \mathrm{C}$ in the short periods when vehicle is stationary. The maximum deviations are $\pm 16^{\circ} \mathrm{C}$ for first scenario and \pm 35 ${ }^{\circ} \mathrm{C}$ for the second.

The control strategies were compared also using the Mean Square Error index in Table I. The addition of ETD control loop proves better results but the price to be paid is an increase of 850 RPM in water pump speed.
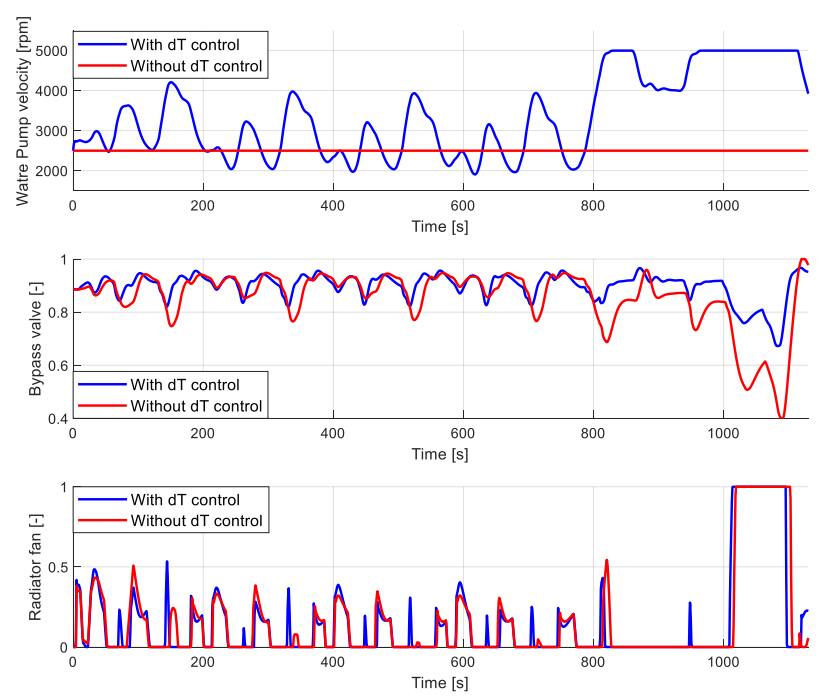

Fig. 8. Comparative results for manipulated values: water pump velocity (up), bypass valve position and radiator's fan PWM duty cycle (down).
TABLE I. CONTROL STRATEGIES COMPARISON - MSE INDEX

\begin{tabular}{|l|c|c|c|}
\hline \multicolumn{4}{|c|}{ Mean Square Error Index } \\
\hline \multicolumn{1}{|c|}{ Signal } & $\begin{array}{c}\text { ETD + ROT } \\
+ \text { ETD }\end{array}$ & $\begin{array}{c}\text { ETD + } \\
\text { ROT }\end{array}$ & $\begin{array}{c}\text { ETD + } \\
\text { ETD }\end{array}$ \\
\hline Engine outlet temperature & 0.82 & 3.35 & - \\
\hline Engine temperature difference & 5.13 & 34.08 & - \\
\hline Radiator outlet teperature & 35.94 & - & 178.64 \\
\hline
\end{tabular}

\section{Conclusions}

This paper presents a control strategy to control the cooling system of an IC engine vehicle that can keep the optimal engine temperature under common driving conditions. First, the cooling system model is presented together with the physical principles of heat exchangers and the nonlinearities of the model are emphasized.

The control design is demanding due to the nonlinearities, variable time constants and variable time delays of the process. Three PI control loop were proposed to control the engine outlet temperature, coolant temperature difference between input and output of the engine and the radiator outlet temperature. The manipulated variables were the bypass valve position, water pump velocity and the radiator's fan duty cycle. The performance of the control strategies was compared using the NEDC driving cycle. It was proved that the addition of the engine temperature difference control loop enhances the overall performance of the control strategy.

\section{References}

[1] J. Heywood, Internal Combustion Engine Fundamentals; McGraw-Hill Education, 1988.

[2] A. Kalelı, G. Kaltakkiran, A. Dumlu and K. K. Ayten, "Design and control of intelligent cooling system for IC engine," International Conference on Engineering and Technology (ICET), Antalya, Turkey, 21-23 Aug. 2017.

[3] C. Brace, H. Burnham-Slipper, R. Wijetunge, N. Vaughan, et al., "Integrated Cooling Systems for Passenger Vehicles," SAE Technical Paper 2001-011248, 2001, doi:10.4271/2001-01-1248.

[4] A. Roberts, R. Brooks, P. Shipway, "Internal combustion engine cold-start efficiency: A review of the problem, causes and potential solutions," Energy Conversion and Management, Vol. 82, Pg. 327-350, June 2014.

[5] R. Cipollone, C. Villant, "A system approach to mathematical modeling of cooling system dynamics," presented at 4th Int. Conf. on Control and Diagnostics in Automotive Applications, Sestri Levante, Italy, 18-20 June, 2003.

[6] N. Gu, J. Ni, "Simulation of Engine Cooling System Based on AMESim," presented at the International Conference on Information and Computing Science, Manchester, UK, 21-22 May, 2009.

[7] K. Khanjani, J. Deng, A. Ordys, "Controlling Variable Coolant Temperature in Internal Combustion Engines and its Effects on Fuel Consumption," in SAE/JSAE 2014 Small Engine Technology Conference \& Exhib., 2014.

[8] T. Castiglione, F. Pizzonia, S. Bova, "A Novel Cooling System Control Strategy for Internal Combustion Engines," SAE Int. J. Mater. Manf., vol. 9, no. 2, pp. 294302, May 2016. 
[9] C. Muresan, G. Harja, "Modeling and controlling the cooling system of an IC vehicle", International Journal of Modeling and Optimization, to be published..

[10] D. Jaume, J. Chantot, "A bond graph approach to the modelling of thermics problems under the hood," Proceedings of IEEE Systems Man and Cybernetics Conference - SMC, Le Touquet, France, 17-20 Oct. 1993.

[11] Barlow TJ, Latham S, McCrae IS, Boulter PG. "A reference book of driving cycles for use in the measurement of road vehicle emissions." IHS; 2009. ISBN 0968-4093

Author Contributions:

Claudiu Muresan carried out the modeling of the cooling system and system identification.

Gabriel Harja designed the control algorithms and testing simulation.

Ioan Nascu proofread the paper.

\section{Creative Commons Attribution License 4.0 (Attribution 4.0 International, CC BY 4.0)}

This article is published under the terms of the Creative Commons Attribution License 4.0

https://creativecommons.org/licenses/by/4.0/deed.en_US 